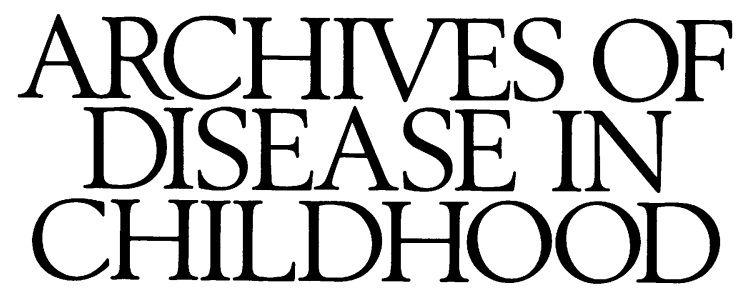

The fournal of the British Paediatric Association

\title{
Annotations
}

\section{Implications of the Children Act for paediatricians}

The Lord Chancellor has stated that the Children Act, which will be implemented in October 1991, represents the biggest reform of law relating to children in living memory. The extent of the change involved is perhaps reflected by the fact that altogether 35 consultation papers will be issued by the Department of Health. To date most of the papers relating to the first phase of consultation have been distributed and the resulting comments will, no doubt, be incorporated in the final regulations and guidance expected early in 1991. Unfortunately the period of time allowed for response became shorter with each batch of papers and this may result in feelings of frustration and discontent.

Paediatricians in general, however, will welcome any changes that make child care law easier to understand and, more importantly, promote and protect the welfare of children. So it is worth exploring some aspects of the act more closely. Many introductory guides have been published. The HMSO publication ${ }^{1}$ and the National Children's Bureau training pack ${ }^{2}$ provide very useful overviews but paediatricians should avoid 'dipping in' if they are to appreciate the full flavour of the act.

\section{The welfare principle}

The welfare of the child is paramount. No court order will be made unless it is clearly beneficial to the child and a checklist is provided to assist in these deliberations. Most of the items on the list are not new but emphasis on the consideration of the wishes and feelings of the child is welcome.

\section{Parental responsibility}

Paediatricians are in regular close contact with parents and their children and already possess well developed 'partnership' skills. The promotion of parental responsibility rather than parental rights will be supported, but paediatricians will have to remember that both parents retain that responsibility after divorce and when their child is being 'looked after' by a local authority.

There is widespread concern that parental interests are not being sufficiently considered. Parental participation at child protection conferences honours the spirit of the act but is viewed less than enthusiastically by many paediatricians.

\section{Children in need}

A child is considered to be in need if:

- He or she is unlikely to achieve or maintain, or to have the opportunity of achieving or maintaining, a reasonable standard of health or development without the provision of services by a local authority;

- Health or development is likely to be significantly impaired, or further impaired, without the provision of such services;

- He or she is disabled.

Each local authority is required to take reasonable steps to identify these children, to provide appropriate services to meet their needs, to promote care within the family, to publish information about the services, and to ensure it is received. The local authority is required to keep a register of disabled children and may make an assessment of need linked to assessments under other legislation-for example, Education Act 1981, Disabled Persons Act 1986. From these requirements flow many implications for paediatricians.

The definition of 'in need' is open to interpretation hedged as it is with words like 'reasonable' and 'significant' and as a term is potentially divisive.

All children should have access to services designed to promote their health and development. As the implementation of the act will take place with no increase in resources, will disadvantaged children have to receive support at the expense of other children? Can it be said with total certainty which services will definitely promote health and development? If not, will that lack of certainty justify a limited provision as no guarantee of improvement is forthcoming? There is therefore understandable concern that resource restraint will result in a limited definition of 'in need' in order to reduce demands on services.

How will children in need be identified? A significant number will be known to the professionals who deliver preschool child health surveillance programmes and the school health service.

Greater attention will now have to be given to children who 'miss out' on surveillance, homeless and travelling families and non-attenders, and consideration given to a more selective approach. Specific groups of children in need include those in care, on child protection registers, and with educational problems.

The definition of disabled will jar with paediatricians but it is the one used in the National Assistance Act 1948 in respect of adults. Entry to the register, which the local authority is required to keep, is voluntary but paediatricians will be familiar with the reluctance of many parents to have the names of their children on handicap registers. Though confusion with child protection registers must be avoided, reassurance will grow if benefits from registration can be demonstrated. Registers relating to many of these children already exist. The community child health service usually maintains a more widely based special needs register that serves to facilitate clinical care and management. The education authority has a register of children with special educational needs. Clearly it would be undesirable to design another separate system to meet the requirements of the act. 
The identification of children in need and disabled children in particular will require close collaboration between health, social services, and education agencies. Procedures whereby information is shared will have to be carefully designed. If they are to be effective more accurate and accessible information systems will have to be developed. Children move in and out of the category 'in need' so the exercise of identification will have to be kept under regular review. To facilitate an integrated approach a common health pathway will have to be established in each health district. Many local authorities will look to the community child health services for an adviser in this matter. Whoever is ultimately identified will need time designated to meet the commitment and adequate administrative support.

\section{Care orders}

The act clearly states that compulsory intervention must be fully justified. Care and supervision orders will require demonstration of 'significant harm'. Harm is defined in the act and consists essentially of a deficit in or detriment to the standard of health, development, and well being that can reasonably be expected for the child in question. The court will have to decide what is 'significant' and will be able to draw.on expert advice. Paediatricians, among others, can be expected to be involved in this advisory process. In order to do so they may need training in order to draft clear, accurate reports and advice about presentation in court.

The status of voluntary care will be abolished. A child will be 'looked after' when in the care of a local authority or when provided with accommodation, which may be in a foster home or children's home or some other appropriate arrangement. A higher profile is given to identification of the health and developmental requirements of these children, many of whom will come into the children in need category. Many local authorities already rely on a medical adviser, frequently recruited from the community child health services, to coordinate identification of needs. Good practice such as this will be expected on a more regular basis and will have resource implications for paediatricians.

\section{Child protection}

The Children Act introduces new protection orders that also have implications for paediatricians. An emergency protection order will replace a place of safety order. It will be made when there is reasonable cause to believe that the child is likely to suffer significant harm if not made 'safe'. The court can give directions for a medical or psychiatric examination or other assessment. As the order can last for only eight days and be extended only once for a further seven days, health agencies will have to be able to react promptly.

Under a child assessment order, which will last for seven days, a court can authorise a health or developmental assessment. The order will be able to specify what is to be done, when the assessment should start, and who should do it. Again, the health professionals involved will have to be reactive, possibly at the expense of other commitments.

Under all these orders a child with sufficient understanding to make an informed decision can refuse to undergo an examination or assessment.

Money from central government has been made available to promote training programmes about the act within social services departments. Regrettably this has not been so for doctors, although individuals have benefited from multidisciplinary training opportunities organised at local level by social services departments. There is still time for this deficit to be corrected.

Assumptions have been made that there will be no significant health resource implications flowing from implementation of the act. Clearly from what has been discussed above this is not true. Even if health agencies wanted to restrict their contributions, it would not be possible to do so as Section 27 of the Children Act allows a local authority to request help from a health authority. Having received a request that authority must comply.

As the act provides an excellent opportunity for better service planning between social services, health, and education, paediatric services will be eager to participate. Coordination of the health participation should be easier in those districts where an integrated child health service has been introduced. Other districts where integration has been rejected or fleetingly discussed could take the opportunity to reconsider their decision.

In all circumstances the health resource implications of implementation of the act must be acknowledged and accommodated within the purchaser and provider plans currently under consideration. Similarly relevant, and possibly new, sevice commitments should be identified when contracts for consultant paediatricians are agreed.

Community Child Health Services,

MARION MILES

Paddington Community Hospital,

$7 A$ Woodfield Road,

London W9 $2 B B$

1 Department of Health. An introduction to the Children Act. London: HMSO, 1989.

2 National Children's Bureau. Working with the Children Act. London: NCB,
1990. See related article on $\mathrm{p} 536$.
Recent research suggests that asthma morbidity in children is on the increase. ${ }^{1}$ This is particularly worrying in the light of evidence that asthma is often poorly managed both by general practitioners and in hospital. ${ }^{23}$ Patients and their carers, for their part, have been criticised for failing to comply with prescribed treatment or to manage attacks appropriately. ${ }^{4}$ Not all the problems, however, are due to poor management: for some patients, asthma can be very difficult to control. 56

Any disease is likely to have some impact on the social and emotional lives of sufferers and their carers. That impact may be greatest where symptoms are not adequately controlled. But even the underlying presence of disease can cause distress and concern. Prevention, avoidance, and management strategies can themselves create difficulties in people's everyday lives. It is also important to recognise that, although sufferers and carers may sometimes claim to lead 'normal' lives, such 'normality' may be based on adjustments and restrictions that they have already incorporated into their lifestyles: their redefinition of normality enables them to emphasise the positive aspects of those lifestyles and avoid focusing on any underlying problems. ${ }^{7}$

In the case of children and their families, the social and emotional impact of asthma can be subdivided into four main categories: social and leisure pursuits, schooling, practical aspects of daily life, and emotional effects. 